\title{
Tuntutan Pekerjaan dan Keterikatan Kerja pada Karyawan Bank: Peran Efikasi Diri sebagai Moderator
}

\author{
Citra Indriani Mandala, Annisaa Miranty Nurendra \\ Program Studi Psikologi, Fakultas Psikologi dan Ilmu Sosial Budaya, Universitas Islam Indonesia, \\ Yogyakarta
}

\begin{abstract}
Abstrak. Karyawan yang memiliki keterikatan kerja yang tinggi penting dimiliki oleh perusahaan agar dapat berkompetisi. Penelitian ini bertujuan untuk mengetahui peran efikasi diri sebagai variabel moderator pada hubungan antara tuntutan pekerjaan dan keterikatan kerja. Penelitian ini melibatkan 90 karyawan di Yogyakarta. Skala yang digunakan dalam penelitian ini adalah adaptasi skala The Utrecht Work Engagement Scale (UWES) (Schaufeli \& Bakker, 2003), skala Tuntutan Pekerjaan (berdasar Schaufeli \& Bakker, 2004), dan skala Efikasi Diri (berdasar Bandura, 1997). Hasil analisis menunjukkan bahwa: (1) Terdapat korelasi negatif antara tuntutan pekerjaan dan keterikatan kerja; (2) Terdapat korelasi positif antara efikasi diri dan keterikatan kerja; (3) Tuntutan pekerjaan dan efikasi diri secara bersama-sama dapat menjadi prediktor bagi tuntutan kerja; dan (4) Tidak terdapat efek moderasi efikasi diri pada hubungan antara tuntutan pekerjaan dan keterikatan kerja. Dapat disimpulkan bahwa, walaupun efikasi diri menjadi prediktor bagi keterikatan kerja, tetapi kuat lemahnya efek tuntutan pekerjaan terhadap keterikatan kerja tidak dipengaruhi oleh kuat lemahnya efikasi diri.
\end{abstract}

Kata Kunci: efikasi diri, keterikatan kerja, tuntutan pekerjaan

\section{Job Demand and Work Engagement among Banking Employees: The Role of Self-Efficacy as Moderator}

Abstract. Employees with high work engagement are important for the company. This study aimed to determine the role of self-efficacy as a moderator variable on the relationship between job demands and work engagement. This study involved 90 employees in Yogyakarta. The scale used in this study was the adaptation scale of The Utrecht Work Engagement Scale (UWES) (Schaufeli \& Bakker, 2003) job demand scale (based on Schaufeli \& Bakker, 2004) and selfefficacy scale (based on Bandura, 1997). The results imply that: (1) There is a negative correlation between job demands and work engagement; (2) There is a positive correlation between self-efficacy and work engagement; (3) Job demands and self-efficacy can be predictors of work engagement; and (4) There is no moderating effect on self-efficacy on the relationship between job demands and work engagement. Therefore, it might be concluded that although self-efficacy is a predictor of work engagement, but the strength of the effects of job demands on work engagement is not influenced by the strength of self-efficacy.

Keywords: job demand, self-efficacy, work engagement

Korespondensi: Annisaa Miranty Nurendra. Email: annisaa.miranty@uii.ac.id 
Menghadapi persaingan yang semakin kompetitif, perusahaan tidak hanya membutuhkan karyawan yang memiliki kemampuan di atas rata-rata. Walaupun begitu, karyawan juga diharapkan mampu menginvestasikan diri sendiri untuk terlibat secara penuh dalam pekerjaan, proaktif, dan memiliki komitmen tinggi terhadap standar kualitas kinerja. Dengan kata lain, perusahaan membutuhkan karyawan yang dapat terikat dengan pekerjaannya (Deviyanti \& Sasono, 2015). Karyawan yang telah bekerja dapat menampilkan kinerja yang maksimal apabila karyawan merasa terlibat di dalam pekerjaan tersebut. Bahkan ketika karyawan merasa tidak terpaksa dalam menjalani apa yang telah menjadi tuntutan pekerjaan, karyawan cenderung mampu memberikan hal yang lebih dari apa yang menjadi tuntutan pekerjaannya. Hal tersebut merupakan suatu indikasi bahwa karyawan tersebut memiliki keterikatan dengan pekerjaan (Puspita, 2012).

Keterikatan kerja menurut Schaufeli dan Bakker (2004) adalah sebuah keterlibatan karyawan secara positif, terlibat secara penuh dalam pekerjaan, dan keadaan pikiran yang berhubungan dengan pekerjaan dengan karakteristik semangat, dedikasi, dan penghayatan. Keterikatan kerja memiliki tiga aspek seperti yang dikemukakan oleh Schaufeli dan Bakker (2004) yaitu: semangat, dedikasi dan penghayatan. Semangat merujuk kepada kemauan karyawan untuk melakukan usaha yang maksimal dalam bekerja. Dedikasi merujuk kepada perasaan karyawan akan pentingnya pekerjaan tersebut, serta merasa bahwa pekerjaan tersebut adalah hal yang menantang. Adapun penghayatan merujuk pada konsentrasi yang penuh saat bekerja dan merasakan pekerjaan tersebut membawa kebahagiaan.

Pada kenyataannya, tidak semua karyawan di organisasi memiliki keterikatan kerja seperti yang diharapkan, seperti yang terjadi pada karyawan bank. Hasil studi awal yang dilakukan peneliti dengan metode wawancara pada tiga subjek karyawan bank menunjukkan bahwa mereka cenderung memiliki keterikatan kerja rendah yang diekspresikan melalui kurang menyukai pekerjaan, mudah lelah, tidak bersemangat, dan minimnya keinginan untuk berusaha. Hal-hal yang memengaruhi kondisi kerja subjek adalah pekerjaan yang dikerjakan dianggap monoton sehingga karyawan cenderung bosan dengan pekerjaan tersebut dan tidak dapat mengembangkan keterampilan yang dimiliki. Karyawan juga cenderung merasa tidak senang ketika mendapat tugas tambahan.

Terdapat dua faktor yang dapat memengaruhi keterikatan kerja karyawan berdasarkan hasil penelitian sebelumnya. Bakker dan Demerouti (2008) mengemukakan bahwa faktor yang memengaruhi keterikatan kerja adalah sumber daya pekerjaan dan sumber daya pribadi. Sumber daya pekerjaan merujuk pada aspek-aspek fisik, sosial, atau organisasional dari pekerjaan tersebut, seperti 
mengurangi tuntutan pekerjaan. Adapun sumber daya pribadi merujuk pada perasaan karyawan terhadap kemampuan yang dimiliki dalam mengontrol diri yang akan berdampak pada keberhasilan pekerjaan tersebut. Salah satu contoh sumber daya pribadi yang dapat memengaruhi keterikatan kerja adalah efikasi diri.

Tuntutan pekerjaan merupakan aspek dari pekerjaan yang berpotensi menyebabkan ketegangan di mana kondisi ini melebihi kemampuan karyawan. Tuntutan kerja mengacu pada aspek fisik, sosial, atau organisasi dari pekerjaan yang memerlukan usaha fisik maupun psikologis secara berkelanjutan (Schaufeli \& Bakker, 2004). Menurut Çiçek (2013), tuntutan pekerjaan dianggap sebagai sebuah tekanan psikologis yang muncul karena bekerja dalam jangka waktu yang panjang, beban kerja yang berlebih dan memiliki waktu yang terbatas untuk melakukan pekerjaan, dan memiliki tuntutan yang saling bertentangan.

Selain faktor tuntutan kerja dan sumber daya kerja, Xanthpoulou et al. (2013) menunjukkan bahwa sumber daya pribadi juga diakui sebagai faktor penentu yang paling penting dari keterikatan kerja. Salah satu sumber daya pribadi yang dapat memengaruhi adalah efikasi diri. Efikasi diri adalah sebuah kepercayaan yang dimiliki individu berkaitan dengan kemampuan yang dimiliki dalam menjalankan sebuah tugas (Bandura, 1997).
Pada hubungan antara tuntutan kerja dan keterikatan kerja, diduga ada efek moderasi dari efikasi diri (Consiglio et al, 2016; Dicke et al., 2018). Tuntutan pekerjaan dianggap sebagai suatu hal yang akan berdampak pada kelelahan apabila karyawan memiliki efikasi diri yang rendah (Bakker et al, 2005; Innanen et al., 2014; Líbano et al., 2012). Hasil penelitian (Crawford et al., 2010) juga menunjukkan bahwa ketika karyawan menilai tuntutan pekerjaan sebagai hambatan, tantangan akan berhubungan negatif dengan keterikatan kerja. Akan tetapi, ketika karyawan menilai tuntutan pekerjaan sebagai tantangan, maka akan tercipta sebuah keterikatan kerja pada karyawan (Xanthopoulou et al., 2013).

Sebaliknya, karyawan dengan efikasi diri tinggi memiliki kepercayaan akan kemampuan dalam mengendalikan lingkungan secara baik. Karyawan dengan efikasi diri yang tinggi akan menganggap tuntutan pekerjaan adalah sebuah hal yang menantang, bukan sebagai hambatan. Karyawan akan menganggap tuntutan pekerjaan sebagai suatu hal yang menguntungkan. Karyawan akan lebih termotivasi sehingga dapat mendorongnya untuk memenuhi tujuan dan untuk mengalami hal positif seperti keterikatan kerja yang dicontohkan dalam usaha yang tinggi, ketekunan, dedikasi, dan penghayatan (Contreras et al, 2020; Líbano et al., 2012; Liou et al, 2020; Llorens et al., 2007). Efikasi diri yang dimiliki karyawan mampu membuat karyawan memberikan usaha-usaha yang 
diperlukan untuk memenuhi tujuan dari pekerjaan tersebut dan menjadi gigih ketika mengalami kesulitan. Dengan adanya kegigihan tersebut, maka karyawan akan memiliki keterikatan kerja (Scheier et al., 1994; Xanthopoulou et al., 2013).
Penelitian ini bertujuan untuk mengeksplorasi hubungan antara tuntutan pekerjaan dan keterikatan kerja yang dimoderatori oleh efikasi diri. Hal ini yang membedakan dengan penelitian-penelitian sebelumnya yang tidak menggunakan variabel moderator.

\section{Gambar 1}

\section{Kerangka Penelitian}

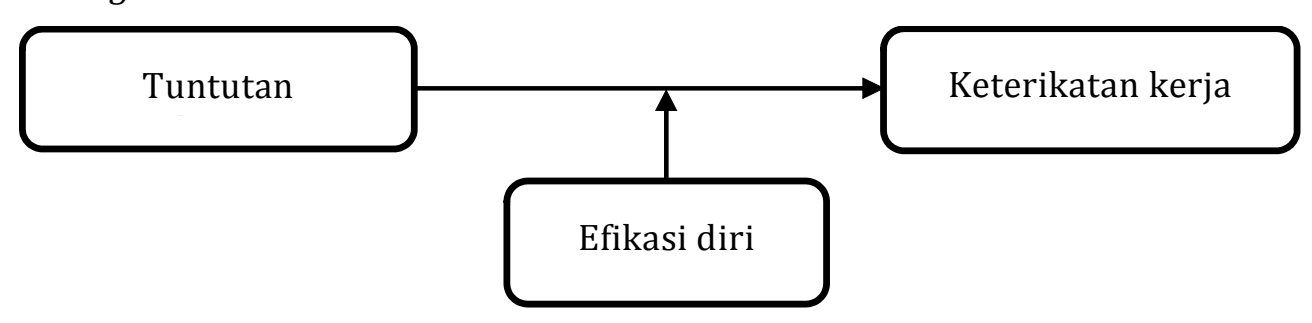

Berdasarkan kerangka penelitian di atas, hipotesis mayor yang diajukan dalam penelitian ini adalah: Terdapat peran efikasi sebagai moderator pada hubungan antara tuntutan kerja dan keterikatan kerja (H4). Sebelum sampai pada hipotesis mayor tersebut, ada beberapa hipotesis minor yang perlu dipenuhi untuk membuktikan adanya efek moderasi, yaitu: (1) Terdapat korelasi negatif antara tuntutan kerja dan keterikatan kerja (H1); (2) Terdapat korelasi positif antara efikasi diri dan keterikatan kerja (H2); (3) Tuntutan kerja dan efikasi diri secara bersama-sama dapat menjadi prediktor terhadap keterikatan kerja (H3).

\section{Metode}

\section{Responden penelitian}

Responden pada penelitian ini adalah 90 karyawan sebuah bank yang bekerja di beberapa kantor cabang di Daerah Istimewa Yogyakarta dengan rentang usia 23 - 55 tahun. Karyawan yang menjadi responden penelitian berjenis kelamin laki-laki dan perempuan, yang menduduki semua level jabatan.

\section{Metode pengumpulan data}

Pengumpulan data dalam penelitian ini menggunakan tiga skala, yaitu skala Keterikatan Kerja, skala Tuntutan Pekerjaan, dan skala Efikasi Diri. Skala Keterikatan Kerja yang digunakan merupakan modifikasi dari The Utrecht Work Engagement Scale (UWES) dari (Schaufeli et al, 2006). Hasil uji validitas dan reliabilitas menghasilkan 24 butir yang sahih. Validitas butir bergerak dari .349 hingga .819 dengan koefisien reliabilitas Alpha Cronbach sebesar 951.

Tuntutan pekerjaan diukur menggunakan aspek-aspekyang dikemukakan 
oleh Schaufeli dan Bakker (2004), yaitu: (a) tuntutan fisik, (b) tuntutan psikis, dan (c) tuntutan organisasi. Berdasarkan hasil analisis, terdapat 11 butir yang sahih. Validitas butir bergerak dari .268 hingga .664 dengan koefisien reliabilitas Alpha Cronbach sebesar .792 .

Efikasi diri diukur menggunakan skala yang dibuat sendiri oleh peneliti berdasarkan teori dari Bandura (1997). Berdasarkan hasil analisis butir, terdapat 28 butir yang sahih. Validitas pada skala efikasi diri bergerak dari .331 hingga .763 dengan koefisien reliabilitas Alpha Cronbach sebesar .935.

\section{Metode analisis data}

Hipotesis dalam penelitian ini diuji dengan menggunakan Moderated Regression Analysis (MRA). Metode MRA atau uji interaksi merupakan aplikasi khusus regresi berganda linier di mana dalam persamaan regresinya mengandung unsur interaksi (perkalian dua atau lebih variabel independen) dengan rumus persamaan sebagai berikut:

$$
\mathrm{Y}=\mathrm{a}+\mathrm{b} 1 \mathrm{X} 1+\mathrm{b} 2 \mathrm{X} 2+\mathrm{b} 3 \mathrm{X} 1 \mathrm{X} 2+\mathrm{e}
$$

Variabel perkalian antara X1 dan X2 disebut juga variabel moderat karena menggambarkan pengaruh moderating variabel X2 terhadap hubungan X1 dan Y. Sedangkan variabel X1 dan X2 merupakan pengaruh langsung dari variabel X1 dan X2 terhadap Y (Liana, 2009).

\section{Hasil}

\section{Deskripsi data penelitian}

Jumlah keseluruhan subjek dalam penelitian ini adalah 90 orang karyawan, yang terdiri dari $63.3 \%$ perempuan (57 orang) dan $36.7 \%$ laki-laki (33 orang). Usia subjek penelitian berkisar dari 23 hingga 55 tahun. Deskripsi subjek penelitian dapat dilihat pada Tabel 1 berikut.

\section{Tabel 1}

Deskripsi Data Penelitian

\begin{tabular}{lcccc}
\hline \multicolumn{1}{c}{ Variabel } & Min & Max & $M$ & $S D$ \\
\hline Keterikatan kerja & 74 & 144 & 105,5 & 15,6 \\
Tuntutan pekerjaan & 17 & 38 & 27,2 & 3,6 \\
Efikasi diri & 72 & 112 & 86,2 & 7,9 \\
Usia (tahun) & 23 & 55 & 32,87 & 7,82 \\
Masa kerja (tahun) & 0,5 & 33 & 8,15 & 7,82 \\
\hline
\end{tabular}

Berdasarkan Tabel 1, peneliti kemudian melakukan kategorisasi data. Kategorisasi dilakukan untuk mengetahui kategorisasi tinggi rendahnya skor yang diperoleh oleh subjek. Deskripsi penggolongan data ke dalam lima kategori dapat dilihat pada Tabel 2 berikut. 
Tabel 2

Kategorisasi Data Penelitian

\begin{tabular}{lcccccc}
\hline \multirow{2}{*}{ Variabel } & \multicolumn{2}{c}{ Keterikatan Kerja } & \multicolumn{2}{c}{ Tuntutan Pekerjaan } & \multicolumn{2}{c}{ Efikasi Diri } \\
\cline { 2 - 7 } & $n$ & $\%$ & $n$ & $\%$ & $n$ & $\%$ \\
\hline Sangat Rendah & 0 & 0 & 1 & 1.11 & 0 & 0 \\
Rendah & 0 & 0 & 20 & 22.22 & 0 & 0 \\
Sedang & 10 & 11.11 & 49 & 54.45 & 9 & 10 \\
Tinggi & 58 & 64.44 & 19 & 21.11 & 72 & 80 \\
Sangat Tinggi & 22 & 24.45 & 1 & 1.11 & 9 & 10 \\
\multicolumn{1}{c}{$N$} & 90 & 100 & 90 & 100 & 90 & 100 \\
\hline
\end{tabular}

Berdasarkan Tabel 2, dapat diketahui bahwa skor keterikatan kerja sebagian besar subjek berada pada kategori tinggi yaitu sebanyak 58 orang dengan persentase sebesar $64.44 \%$. Selanjutnya, kategori sangat tinggi sebanyak 22 orang dengan persentase sebesar $24.45 \%$, dan 10 orang berada pada kategori sedang dengan persentase sebesar $11.11 \%$. Tidak terdapat subjek yang memiliki skor pada kategori sangat rendah dan rendah di mana kategori tersebut memiliki persentase sebesar $0 \%$.

Pada variabel tuntutan pekerjaan, sebagian besar subjek berada pada kategori sedang yaitu sebanyak 49 orang dengan persentase sebesar $54.45 \%$. Selanjutnya kategori rendah sebanyak 20 orang dengan persentase $22.22 \%$. Kategori tinggi sebanyak
19 orang dengan persentase $21.11 \%$. Terakhir kategori sangat rendah dan sangat tinggi memperoleh persentase yang sama yaitu sebesar 1.11\% dengan jumlah subjek sebanyak satu orang di setiap kategori.

Selanjutnya kategorisasi juga dilakukan pada data skala efikasi diri. Berdasarkan Tabel 2, dapat diketahui bahwa sebagian besar subjek berada pada kategori tinggi yaitu sebanyak 72 orang dengan persentase sebesar $80 \%$. Selanjutnya, kategori sangat tinggi sebanyak sembilan orang dengan persentase sebesar $10 \%$, dan sembilan orang berada pada kategori sedang dengan persentase sebesar $10 \%$. Tidak terdapat subjek yang berada pada kategori sangat rendah dan rendah, di mana kategori tersebut memiliki persentase sebesar $0 \%$.

\section{Tabel 3}

Hasil Uji Hipotesis

\begin{tabular}{|c|c|c|c|}
\hline Variabel & $R$ & $p$ & $\begin{array}{c}R^{2} \\
\text { change }\end{array}$ \\
\hline Tuntutan pekerjaan * Keterikatan kerja & -.215 & .008 & - \\
\hline Efikasi diri * Keterikatan kerja & .388 & .000 & - \\
\hline Tuntutan pekerjaan ${ }^{*}$ Efikasi diri ${ }^{*}$ Keterikatan kerja 1 & .413 & .008 & .106 \\
\hline Tuntutan pekerjaan * Efikasi diri ${ }^{*}$ Keterikatan kerja ${ }^{2}$ & .422 & .133 & .007 \\
\hline
\end{tabular}

Catatan. ${ }^{1}=$ Variabel efikasi diri sebagai variabel bebas; ${ }^{2}=$ Variabel efikasi diri sebagai variabel moderator. 


\section{Uji hipotesis}

Hasil uji regresi antara tuntutan pekerjaan dan keterikatan kerja menghasilkan koefisien sebesar $-.215(p=.000, p<.01)$. Selanjutnya, hasil uji regresi antara efikasi diri dan keterikatan kerja memiliki koefisien sebesar .388 ( $p=.000, p<.01)$. Hasil uji regresi dengan variabel tuntutan pekerjaan dan efikasi diri menunjukkan kedua variabel mampu menjadi prediktor bagi variabel keterikatan kerja dengan nilai koefisien regresi sebesar .413 $(p<.01)$. Dengan demikian, hipotesis $\mathrm{H} 1, \mathrm{H} 2$, dan $\mathrm{H} 3$ dapat diterima.

Metode MRA dilakukan dengan variabel interaksi antara variabel tuntutan kerja dan efikasi diri yang akan dihitung efek moderasinya. Hasil uji MRA menunjukkan nilai koefisien regresi sebesar.422 ( $p>$.05). Hal ini menunjukkan bahwa variabel efikasi diri tidak memiliki peran yang signifikan sebagai variabel moderator pada hubungan antara tuntutan pekerjaan dan keterikatan kerja. Rendahnya signifikansi ini juga tampak dari tidak signifikannya perubahan nilai koefisien determinasi model regresi dengan melibatkan variabel efikasi diri sebagai variabel moderator hanya mengakibatkan perubahan sumbangan efektif sebesar .007, dengan perubahan nilai rasio Fisher sebesar 766 ( $p>$.05) yang sifatnya kecil dan tidak signifikan. Oleh karena itu, hipotesis mayor H4 yang menyatakan adanya hubungan antara tuntutan pekerjaan dan tinggi rendahnya keterikatan kerja akan dipengaruhi oleh efikasi diri sebagai moderator dinyatakan ditolak.

\section{Pembahasan}

Tujuan penelitian ini untuk mengetahui hubungan antara tuntutan pekerjaan dan keterikatan kerja yang dimoderatori oleh efikasi diri. Sebelum menguji hipotesis mayor tersebut, terdapat beberapa hipotesis minor yang diuji oleh peneliti, yaitu: (1) Terdapat korelasi negatif antara tuntutan kerja dan keterikatan kerja; (2) Terdapat korelasi positif antara efikasi diri dan keterikatan kerja; dan (3) Tuntutan kerja dan efikasi diri secara bersama-sama dapat menjadi prediktor terhadap keterikatan kerja.

Hipotesis yang menyatakan bahwa terdapat korelasi negatif antara tuntutan kerja dan keterikatan kerja dinyatakan diterima. Hasil penelitian ini sejalan dengan penelitian Thirapatsakun et al (2014) yang menunjukkan bahwa terdapat hubungan negatif antara tuntutan pekerjaan dan keterikatan kerja. Subjek penelitian tersebut adalah perawat di rumah sakit umum di Thailand. Hasil penelitian tersebut menunjukkan bahwa tingginya aktivitas tuntutan pekerjaan di rumah sakit berdampak negatif pada keterikatan kerja yang dimiliki oleh karyawan. Tuntutan pekerjaan membuat karyawan menunjukkan perasaan yang negatif dan membuat karyawan semakin tegang ketika bekerja. Hal tersebut berdampak pada menurunnya keterikatan kerja karyawan. Berdasarkan pemaparan 
Bakker dan Demerouti (2008), terdapat dua faktor yang memengaruhi keterikatan kerja, salah satunya adalah dengan mengurangi tuntutan pekerjaan. Tuntutan pekerjaan memerlukan usaha yang berlebih dari karyawan. Usaha yang diberikan dapat berupa usaha fisik maupun psikologis (Schaufeli \& Bakker, 2004). Usaha yang berlebih ini akan membuat karyawan mudah lelah. Tuntutan pekerjaan yang tinggi dapat memengaruhi keterikatan kerja yang dimiliki oleh karyawan (Bakker \& Demerouti, 2008). Hasil penelitian (Crawford et al, 2010) menunjukkan bahwa ketika karyawan menilai tuntutan pekerjaan sebagai hambatan, maka tuntutan pekerjaan akan berhubungan negatif dengan keterikatan kerja.

Hipotesis kedua yang diuji adalah terdapat korelasi positif antara efikasi diri dan keterikatan kerja. Berdasarkan hasil analisis hipotesis ini dinyatakan diterima. Hasil ini sejalan dengan penelitian yang dilakukan oleh Libano et al. (2012) yaitu menunjukkan bahwa ada hubungan positif antara efikasi diri dan keterikatan kerja. Karyawan dengan efikasi diri yang tinggi akan merasa memiliki banyak sumber daya dan merasa memiliki tuntutan pekerjaan yang rendah. Karyawan dengan efikasi diri tinggi akan memiliki keterikatan kerja yang tinggi dibandingkan dengan karyawan yang memiliki efikasi diri yang rendah. Luthans dan Youssef (2007) mengungkapkan bahwa karyawan dengan sumber daya pribadi yang tinggi lebih cenderung dapat menginvestasikan energi untuk mencapai sebuah harapan dan tujuan mereka. Efikasi diri yang dimiliki mampu membuat karyawan memberikan energi yang diperlukan untuk memenuhi tujuan dari pekerjaan tersebut dan menjadi gigih dalam menghadapi kesulitan. Adanya kegigihan tersebut, membuat karyawan akan memiliki keterikatan kerja (Xanthopoulou et al., 2013).

Hipotesis ketiga menyatakan tuntutan kerja dan efikasi diri secara bersama-sama dapat menjadi prediktor terhadap keterikatan kerja. Hasil analisis menunjukkan hipotesis ini dinyatakan diterima. Seperti yang telah dibahas sebelumnya bahwa terdapat dua faktor yang memengaruhi keterikatan kerja, antara lain tuntutan pekerjaan dan sumber daya pribadi. Sumber daya pribadi yang diangkat dalam penelitian ini adalah efikasi diri. Hasil analisis dalam penelitian ini menunjukkan bahwa tuntutan pekerjaan dan keterikatan kerja memiliki korelasi yang negatif dan signifikan, sedangkan efikasi diri dan keterikatan kerja memiliki korelasi yang positif dan signifikan. Hasil penelitian (Xanthopoulou et al., 2009) menunjukkan bahwa sumber daya pribadi dan sumber daya kerja telah diakui sebagai faktor penentu yang paling penting dari keterikatan kerja. Keterkaitan kedua variabel tersebut dijelaskan di mana karyawan yang menilai tuntutan pekerjaan sebagai tantangan maka akan tercipta sebuah keterikatan kerja pada karyawan. Karyawan akan menganggap tuntutan pekerjaan sebagai 
tantangan ketika karyawan memiliki sumber daya yang tinggi (Xanthopoulou et al, 2013).

Selanjutnya, analisis moderasi menggunakan regresi juga dilakukan pada tiga variabel penelitian yaitu tuntutan pekerjaan, keterikatan kerja, dan efikasi diri yang bertindak sebagai moderator pada penelitian ini. Pada hasil analisis menggunakan analisis regresi berjenjang yang menunjukkan bahwa terdapat korelasi yang tidak signifikan antara variabel interaksi dan keterikatan kerja. Hal ini menunjukkan bahwa efikasi diri tidak memiliki efek moderasi pada hubungan antara tuntutan pekerjaan dan keterikatan kerja. Artinya, kuat lemahnya pengaruh tuntutan pekerjaan terhadap keterikatan kerja tidak ditentukan oleh efikasi diri. Korelasi antara tuntutan pekerjaan dan keterikatan kerja bersifat langsung. Begitu pula korelasi antara efikasi diri dan keterikatan kerja. Hasil penelitian ini tidak sejalan dengan penelitian yang dilakukan oleh Xanthopoulou et al. (2013). Hasil penelitian tersebut menunjukkan bahwa terdapat efek interaksi penuh di mana tuntutan yang tinggi dan efikasi diri yang tinggi akan menghasilkan keterikatan kerja yang tinggi. Sementara kombinasi antara tuntutan yang tinggi dan efikasi diri yang rendah akan mengakibatkan rendahnya keterikatan kerja. Hasil ini menunjukkan bahwa keterikatan kerja karyawan akan menurun ketika karyawan bekerja di lingkungan yang tidak memiliki sumber daya kerja. Hubungan antara efikasi diri dan keterikatan kerja menjadi sangat positif ketika karyawan menggunakan efikasi diri tersebut untuk mengontrol lingkungan kerja dan kemudian menjadi terikat dengan pekerjaan mereka. Karyawan yang memiliki sumber daya yang tinggi perlu adanya tantangan dalam lingkungan kerja agar dapat terikat dengan pekerjaannya. Tuntutan pekerjaan itulah yang menjadi tantangan bagi karyawan.

Hasil penelitian ini juga tidak sesuai dengan studi dari Salanova et al. (2006) yang meneliti efek moderasi efikasi diri pada hubungan antara tuntutan pekerjaan dan perilaku koping. Hasil penelitian tersebut menunjukkan adanya peran moderator efikasi diri antara tuntutan pekerjaan dan perilaku koping. Penelitian tersebut menunjukkan bahwa laki-laki lebih memiliki perilaku koping yang tinggi dibandingkan perempuan. Efikasi diri dapat meningkatkan perilaku koping dan dapat mengurang koping pasif. Terdapat efek interaksi antara tuntutan pekerjaan dan efikasi diri terhadap peningkatan perilaku koping, di mana karyawan dengan efikasi diri tinggi akan menganggap sebuah tuntutan pekerjaan sebagai sebuah tantangan.

Seharusnya efek moderasi efikasi diri dapat dijelaskan menurut proses model Resources-Experiences-Demands

(RED) (Líbano et al., 2012), ketika karyawan memiliki efikasi diri yang rendah, karyawan memiliki kepercayaan untuk tidak mampu mengontrol lingkungan kerja secara efektif. Situasi ini memerlukan upaya yang berkelanjutan dan 
akibatnya dapat menguras sumber daya karyawan dan menyebabkan kehabisan energi serta masalah kesehatan. Karyawan dengan efikasi diri yang rendah akan mempersepsikan tuntutan pekerjaan sebagai suatu hal yang dapat membuat karyawan mengalami kelelahan yang berat. Efikasi diri bertindak sebagai proses motivasional yang mengarahkan pada persepsi sumber daya kerja yang lebih. Ketika efikasi diri tinggi, karyawan percaya akan mampu mengendalikan lingkungan kerja secara baik, lebih mungkin mengalami tuntutan pekerjaan yang rendah, dan lebih banyak memiliki sumber daya kerja. Dengan demikian, karyawan dengan efikasi diri tinggi akan menganggap tuntutan pekerjaan sebagai suatu hal yang menantang dan bukan sebagai hambatan. Hal ini akan membuat karyawan memberikan energi berlebih untuk pekerjaan sehingga terciptanya keterikatan kerja. Keterikatan kerja karyawan akan menurun ketika karyawan bekerja di lingkungan yang tidak memiliki sumber daya kerja. Hubungan antara efikasi diri dan keterikatan kerja menjadi positif ketika karyawan menggunakan efikasi diri tersebut untuk mengontrol lingkungan kerja dan kemudian menjadi terikat dengan pekerjaan mereka. Karyawan yang memiliki sumber daya yang tinggi perlu adanya tantangan dalam lingkungan kerja agar dapat terikat dengan pekerjaannya. Dalam hal ini, tuntutan pekerjaan dapat menjadi tantangan tersebut (Xanthopoulou et al, 2013).
Hasil penelitian ini menunjukkan efikasi diri tidak memiliki efek moderasi terhadap tuntutan pekerjaan dan keterikatan kerja. Artinya, kuat lemahnya pengaruh tuntutan pekerjaan dan keterikatan kerja tidak dipengaruhi oleh efikasi diri. Pada hasil deskripsi data penelitian didapatkan bahwa keterikatan kerja dan efikasi diri yang dimiliki subjek berada pada kategori tinggi, sedangkan tuntutan pekerjaan yang dirasakan subjek berada pada kategori sedang. Efikasi diri tidak memberikan efek moderasi karena tuntutan yang dirasakan berada pada kategori sedang, di mana karyawan tidak dapat menggunakan efikasi diri tersebut untuk mengontrol lingkungan dan menjadi lebih terikat dengan pekerjaan. Efikasi diri akan memberikan efek moderasi ketika tuntutan yang dirasakan tinggi. Ketika tuntutan yang dirasakan tinggi, maka karyawan menggunakan sumber daya pribadi, yaitu efikasi diri untuk mengontrol lingkungan dan menjadi lebih terikat dengan pekerjaannya (Xanthopoulou et al, 2013).

Penelitian ini memiliki keterbatasan, yaitu data dalam penelitian ini tidak memenuhi asumsi normal, karena subjek cenderung memberikan jawaban pada kategori tinggi. Oleh karena itu, hasil penelitian ini merupakan indikasi dan belum dapat digeneralisasikan pada populasi yang lebih luas.

\section{Simpulan}

Berdasarkan hasil analisis data dan pembahasan hasil dapat disimpulkan bahwa 
efikasi diri tidak memiliki pengaruh moderasi pada hubungan antara tuntutan pekerjaan dan keterikatan kerja. Artinya, kuat lemahnya pengaruh tuntutan pekerjaan terhadap keterikatan kerja tidak ditentukan oleh efikasi diri.

\section{Saran}

Berdasarkan penelitian yang telah dilakukan dan hasil yang diperoleh, maka dengan ini penulis memiliki beberapa saran. Penelitian selanjutnya disarankan memperluas sampel penelitian sehingga kriteria normalitas data sebisa mungkin dapat terpenuhi. Pada subjek yang terbatas, perlu menggunakan teknik analisis statistika yang dapat digunakan pada data yang tidak normal. Sementara itu, untuk aplikasi secara praktis, organisasi disarankan untuk lebih memperhatikan keseimbangan tuntutan pekerjaan dan meningkatkan sumber daya pekerjaan karena tuntutan pekerjaan yang tinggi akan berdampak kepada keterikatan kerja karyawan.

\section{Referensi}

Bakker, A. B., \& Demerouti, E. (2008). Towards a model of work engagement. Career Development International, 13(3), 209223 .https: // doi.org/ 10.1108 / 13620430810870476

Bakker, A. B., Demerouti, E., \& Euwema, M. C. (2005). Job resources buffer the impact of job demands on burnout. Journal of Occupational Health Psychology, 10(2), 170-180. https://doi.org/10.1037/ 1076-8998.10.2.170
Bandura, A. (1997). Self-efficacy: The exercise of control. W H Freeman/Times Books/ Henry Holt \& Co.

Çiçek, I. (2013). Relationship between balance of job demands-control and shared mission/vision for blue-collar employees. Social and Behavioral Sciences, 99, 1093 - 1104. https:// doi.org/10.1016/j.sbspro.2013.10.583

Consiglio, C., Borgogni, L., Tecco, C. Di, \& Schaufeli, W. B. (2016). What makes employees engaged with their work? The role of self-efficacy and employee's perceptions of social context over time. Career Development International, 21(2), 125-143. https://doi.org/10.1108/CDI03-2015-0045

Contreras, F., Espinosa, J. C., \& Esguerra, G. A. (2020). Could personal resources influence work engagement and burnout? A study in a group of nursing staff. SAGE Open, 10(1), 2158244019900563. https://doi.org/ $10.1177 / 2158244019900563$

Crawford, E. R., LePine, J. A., \& Rich, B. L. (2010). Linking job demands and resources to employee engagement and burnout: $A$ theoretical extension and meta-analytic test Journal of Applied Psychology, 95(5), 834-848. https://doi.org/10.1037/ a0019364

Deviyanti, A. D., \& Sasono, A. D. (2015). Pengaruh sumber daya pekerjaan (job resources) dengan keterikatan kerja (work engagement) sebagai mediator terhadap perilaku proaktif (Studi pada karyawan PT RGA International Indonesia). Jurnal Ilmu Manajemen MAGISTRA, 1(1), 16-30.

Dicke, T., Stebner, F., Linninger, C., Kunter, M., \& Leutner, D. (2018). A longitudinal study of teachers' occupational wellbeing: Applying the job demandsresources model. Journal of Occupational Health Psychology, 23(2), 262-277. https://doi.org/10.1037/ ocp0000070 
Innanen, H., Tolvanen, A., \& Salmela-Aro, K. (2014). Burnout, work engagement and workaholism among highly educated employees: Profiles, antecedents and outcomes. Burnout Research, 1(1), 3849. https://doi.org/https://doi.org/ 10.1016/j.burn.2014.04.001

Liana, L. (2009). Penggunaan MRA dengan SPSS untuk menguji pengaruh variabel moderating terhadap hubungan antara variabel independen dan variabel dependen. Dinamik, 14(2), 90-97. https:/ /www.unisbank.ac.id/ojs/index.php/ $\mathrm{fti1/article/view/95}$

Libano, M. ., Llorens, S., Salanova, M., \& Schaufeli, W. . (2012). About dark and bright side of self efficacy: workaholism and work engagement. The Spanish Journal of Psychology, 15(2), 688-701. h t tp s: / / doi.org / 10.5209 / rev_SJOP.2012.v15.n2.38883

Liou, Y.-H., Daly, A. J., Downey, C., Bokhove, C., Civís, M., Díaz-Gibson, J., \& López, S. (2020). Efficacy, explore, and exchange: Studies on social side of teacher education from England, Spain, and US. International Journal of Educational Research, 99, 101518. https://doi.org/ https: / / doi.org / 10.1016 / j.ijer.2019.101518

Llorens, S., Schaufeli, W., Bakker, A., \& Salanova, M. (2007). Does a positive gain spiral of resources, efficacy beliefs and engagement exist? Computers in Human Behavior, 23(1), 825-841. https://doi.org/ ht tps: / / doi.org / 10.1016 / j.chb.2004.11.012

Luthans, F., \& Youssef, C. M. (2007). Emerging positive organizational behavior. Journal of Management, 33(3), 321-349. h t tp s://doi.org / 10.1177 / 0149206307300814

Puspita, M. D. (2012). Hubungan antara dukungan sosial dan makna kerja sebagai panggilan (Calling) dengan keterikatan kerja. Jurnal Ilmiah
Mahasiswa Universitas Surabaya, 1(1), 1-17.

Salanova, M., Grau, R. ., \& Martínez, I. . (2006). Job demand and coping behavior: The moderating role of professional selfefficacy. Psychology in Spain, 10(1), 1-8.

Schaufeli, W. B, \& Bakker, A. B. (2003). UWES, Utrecht Work Engagement Scale. Occupational Health Psychology Unit Utrecht University. https://doi.org/ 10.1037/t07164-000

Schaufeli, W.B., \& Bakker, A. B. (2004). Job demands, job resources, and their relationship with burnout and engagement: a multi-sample study. Journal of Organizational Behavior, 25, 293-315. https://doi.org/10.1002/ job.248

Schaufeli, Wilmar B, Bakker, A. B., \& Salanova, M. (2006). The measurement of work engagement with a short questionnaire: A cross-national study. Educational and Psychological Measurement, 66(4), 7017 16.https: // doi.org/10.117 / / 0013164405282471

Scheier, M. F., Carver, C. S., \& Bridges, M. W. (1994). Distinguishing optimism from neuroticism (and trait anxiety, selfmastery, and self-esteem): A reevaluation of the Life Orientation Test. Journal of Personality and Social Psychology, 67(6), 1063-1078. https:// doi.org/10.1037/0022-3514.67.6.1063

Thirapatsakun, T., Kuntonbutr, C., \& Mechinda, P. (2014). The relationships among job demands, work engagement, and turnover intentions in the multiple groups of different levels of perceived organizational supports. Universal Journal of Management, 2(7), 272-285. https: / / doi.org/10.13189/ ujm.2014.020703

Xanthopoulou, D., Bakker, A. B., Demerouti, E., \& Schaufeli, W. B. (2009). Reciprocal relationships between job resources, personal 
resources, and work engagement. Journal of Vocational Behavior, 74(3), 235-244. https://doi.org/ https://doi.org/10.1016/ j.jvb.2008.11.003

Xanthopoulou, D., Bakker, A. B., \& Fischbach, A. (2013). Work engagement among employees facing emotional demands:
The role of personal resources. Journal of Personnel Psychology, 12(2), 74-84. https://doi.org/10.1027/1866-5888/ a000085

Received 7 February 2020

Revised 30 May 2020

Accepted 30 May 2020 
